УДК 378.1

DOI 10.23951/2307-6127-2020-1-113-120

\title{
ПРОФЕССИОНАЛЬНАЯ ПОДГОТОВКА БАКАЛАВРОВ В ПАРАМЕТРАХ ИНТЕЛЛЕКТУАЛИЗАЦИИ КАК ВЕДУЩЕГО ОРИЕНТИРА ВЫСШЕЙ ШКОЛЫ
}

\author{
Г. И. Егорова, С. П. Семухин ${ }^{1}$ Б. М. Чабарова ${ }^{2}$ \\ ${ }^{1}$ Тюменский индустриальный университет, Тюмень \\ ${ }^{2}$ Тюменский государственный университет, Тюмень
}

Показано новое социокультурное видение принципа интеллектуализации, ориентированного на развитие интеллектуальной культуры бакалавров с различных позиций. Материалом для исследования стала система развития интеллектуальной культуры бакалавров высшей школы, где системообразующим принципом явился принцип интеллектуализации. Проведен теоретико-методологический анализ ведущих концепций по исследуемой теме, контент-анализ, сравнительный, сопоставительный анализ. В ходе изучения педагогического опыта использовался метод классификации, аналогий. Эмпирические методы включали анкетирование, беседу, сравнительный анализ. Статистическая обработка данных проводилась с помощью методов математического анализа. Показаны ведущие методологические подходы, функциональное значение принципа интеллектуализации как особого ориентира, необходимого при реализации ФГОС нового поколения в высшей школе. Раскрыто психолого-педагогическое значение, обоснована трендовость интеллектуализации как ведущего направления и общественная необходимость развития российского образования на перспективу с учетом международных вызовов: инновационности, информатизации, развития нано-, био-, когнито-, инфотехнологий, процессов интеграции, требований работодателя. Педагогический взгляд раскрывает принцип интеллектуализации в повышении качества подготовки бакалавров в вузе. Социокультурный аспект реализации принципа интеллектуализации обеспечивает профессиональный рост, карьеру бакалавров на ближайший и долгосрочный периоды. Особое внимание сфокусировано на возможностях проявления принципа интеллектуализации через параметры деятельности, структуры содержания, уровневых показателей развития интеллектуальной культуры бакалавров. Доказана эффективность реализации системы развития интеллектуальной культуры бакалавров, где системообразующим элементом системы стал принцип интеллектуализации. Определены уровни развития интеллектуальной культуры, основные виды деятельности в учебной, научно-исследовательской работе по следующим показателям: деятельность на учебном занятии; научно-исследовательская деятельность; культура умственного труда бакалавра; рефлексивная деятельность; опыт коммуникативного взаимодействия. Показатели развития интеллектуальной культуры анализировались и учитывались на каждом курсе (с первого по четвертый) для бакалавриата по техническим и педагогическим направлениям. Доказано, что принцип интеллектуализации - это ключевая стратегия, ориентир, обеспечивающий высокий уровень развития интеллектуальной культуры будущего бакалавра различных направлений. Реализация принципа интеллектуализации встраивается в содержательный и деятельностный компоненты образования и предполагает активную включенность будущих бакалавров в научно-практическую деятельность, ориентирующую на получение конкретного результата, что обеспечивает в будущем профессиональный успех бакалавров.

Ключевые слова: принщип интеллектуализации, профессиональная подготовка, интеллектуальная культура, качество подготовки. 
Современный период развития российского общества строится с применением в широких масштабах знаний, инновационных технологий, информации [1]. При этом глобальные перемены и новая история развития России характеризуются накоплением и приумножением интеллектуальных и культурных достижений Российского государства, т. е. становится очевидным переход на новый тип развития общества, основанного на знаниях, мыслительных операциях, умениях. Сегодня обоснованность радикальной перестройки подготовки бакалавров связана с рядом международных вызовов, которые ставят перед педагогами новые задачи, решение которых определит содержание образования, новые формы и методы профессиональной подготовки [2]. Среди ярких, значимых вызовов для промышленности, науки, образования выделим следующие: конвергенция, информатизация, когнитивность, интеллектуализация. Среди первых вызовов - идеи конвергенции, ориентированные на объединение и взаимопроникновения естественно-научных, гуманитарных наук о человеке, животных, информационных систем. В любой образовательной системе идеи конвергенции проявляются через реализацию принципов учета межпредметных связей, процессов интеграции.

Информатизационный вызов связан с созданием новой информационной среды, развитием информационных технологий, культуры работы с информацией, средствами образования (сетевые, облачные, дистантные).

Когнитивный вызов ориентирует на сознательное развитие когнитивности личности, совершенствование методов познания, обеспечивающих реализацию идей опережающего образования, опережающей экономики, экономики знаний.

Необходимость интеллектуализации деятельности проявляется как на производстве, в науке, так и в образовании. Образовательный уровень интеллектуализации связан с необходимостью высокого уровня развития сознания, умственного и мыслительного аппарата каждого человека. Производственный уровень ориентирован на процессы интеллектуализации труда в рамках новых требований экономики знаний, реализации инновационных идей на производстве. Данный параметр интеллектуализации показывает значение и роль образования, его необходимость на период всей жизни человека, учет интеллектуальных умений (реагирование, рациональность мышления, работа в нестандартных условиях).

Рассмотренные вызовы четко показывают необходимость использования так называемых NBIC-технологий: микротехнологии (нано); биологических, информационных, когнитивных, взаимопроникновение которых выстраивается с учетом принципа интеллектуализации образовательной деятельности.

Проведенный теоретико-методологический анализ понятия «интеллектуализация» раскрывает его как некоторый принцип, ориентированный на развитие интеллектуальной культуры человека и общества. Исследования ряда ученых (П. И. Пидкасистый, Л. М. Фридман) указывают на путь проявления принципа интеллектуализации - рациональная готовность студента к саморазвитию, самообразованию [3] через проявление значимых компонентов: в частном видеть общее; из общего выделять конкретное; прогнозировать механизмы образования понятий; осознавать единое и целое; уметь сравнивать научность понятия с реальной жизненной ситуацией; осознавать собственные знания, умения, навыки; прогнозировать систематичность познания. С позиции новосибирской научной школы философов (исследования профессора И. С. Ладенко и др.), делающей акцент на вопросах прогноза интеллектуального развития общества, отмечено, что интеллектуализация - система управления реформами образования, процесс подготовки интеллектуалов - высокоразвитых специалистов, основанный на развитии самосознания $[4,5]$. Далее специалисты с помощью своего самосознания ориентируются на развитие и обновление своей интеллектуальной культуры [4, с. 50]. 
Обзор научных статей, монографий позволил определить эффективность подготовки бакалавров высшей школы с учетом принципа интеллектуализации, который проявляется через развитие научного мировоззрения, обогащающее мышление приемами научного познания; развитие качества знаний (системность, научность, критичность, динамичность, познавательные стратегии); развитие механизмов мышления, моделирования, целеполагания; преобразования содержания в сторону развития творчества, воображения, критичности [6-8].

Мы рассматриваем принцип интеллектуализации как стратегический ориентир, направленный на развитие интеллектуальной культуры бакалавра. При этом мы не исключаем и тот факт, что принцип интеллектуализации работает совместно с рядом других востребованных принципов, которые эффективно проявляются в подготовке бакалавров различных направлений. Кроме известных дидактических принципов (научности, доступности, связи с жизнью), реализуемых в образовательной деятельности, отметим те, которые востребованы в условиях реализации ФГОС. Принцип развития педагогов, бакалавров приоритетная задача реализации ФГОС, который проявляется через приемы развития студентов путем интерактивных, развивающих технологий, тренингов, проектов. Принцип инициативности и лидерства определяет ответственность за результат, инициативность при решении конкретной задачи. Принцип ориентации на результат делает акцент на конечном результате, а не на пути достижения. Принцип меритократии - каждому студенту по заслугам, результат каждого прозрачен по точкам контроля, показателям. Принцип сотрудничества и работы в команде показывает, что школа - единая команда, помощь другому поможет достичь успеха самому. Принцип доверия, взаимоуважения, надежности, ориентированный на уважение к другому человеку, независимо от языка, национальности, этничности.

Научно-педагогический дискурс принципа интеллектуализации выявляет его функциональное значение, которое проявляется в уровне развития интеллектуальной культуры бакалавра. Этот основополагающий тезис подтверждается с различных позиций научного знания. С позиции психолого-педагогического, классического осмысления используем такие характеристики, как мыслительные операции, мышление в действии, развертывание мышления, переход от простого к глобальному мировоззрению через процессы анализа, синтеза, сравнения, установление причинно-следственных связей.

Если говорить о данном принципе с позиции классического социального осмысления, то можно утверждать об особых интеллектуальных характеристиках личности обучающегося, погруженной в социально-культурные контексты жизнедеятельности [9].

Каждый принцип в образовательной деятельности - это руководство к действию как педагога, так и для обучающегося. Теперь очевиден и напрашивается другой вопрос: можно ли рассматривать принцип интеллектуализации как особое руководство в образовательной деятельности в высшей школе, итогом которого является высокий уровень интеллектуальной культуры? Ответ на этот вопрос уже был определен рядом авторов научной школы (г. Новосибирск). Научные идеи новосибирской школы философов легли в основу разработки системы развития интеллектуальной культуры обучающихся, при этом центральным системообразующим принципом стал принцип интеллектуализации.

Философское осмысление интеллектуальной культуры как основы становления инновационного общества наиболее полно разработано профессором И. С. Ладенко (новосибирская научная школа) [5]. В своей работе «Проблемы интеллектуального развития общества в условиях научно-технического прогресса» автор определяет необходимые и значимые ключевые факторы развития интеллектуальной культуры общества в параметрах 
глобальных и локальных изменений. Прежде всего это процессы миграции, низкий уровень развития духовно-нравственных качеств, культуры мышления при выполнении конкретных задач, которые в большей степени определяют и формируют профессиональный уровень будущих бакалавров.

Приведем некоторые результаты и их обсуждение. Интеллектуальная культура как интегральное понятие играет приоритетную роль в системе социального взаимодействия, обеспечивает качество профессиональной подготовки [10]. Остановимся на некоторых особенностях и показателях развития интеллектуальной культуры человека в целом.

Среди выделенных критериев приоритетны два: интеллектуальная компетентность, готовность к жизнедеятельности. Интеллектуальную компетентность (ИК) - познавательную емкость формирует готовность к профессиональной деятельности, включает совокупность интеллектуальных умений, которые задают широту познавательной деятельности [11]. Готовность к жизнедеятельности позволяет оценивать и наращивать собственные ресурсы, осуществлять рефлексию, благодаря которой личность становится во внешнюю позицию по отношению к своей интеллектуальной культуре.

Методологические основы исследования определены совокупностью подходов. Культурологический подход - это мировоззренческая база для встраивания гуманности, нравственности в понятие «интеллектуальная культура». Эти качества сформировались у лучших представителей российской науки, деятелей культуры. Системный подход необходим и рассматривает понятие «интеллектуальная культура» как некоторую систему структурных компонентов, которые мы соотносим и сочетаем с системой профессиональной подготовки специалиста и бакалавра [12].

Процессуальные характеристики развития интеллектуальной культуры рассматриваем с позиций деятельностного, синергетического подходов и их качественных характеристик. Характеристика синергетических взаимодействий и проявлений происходит с учетом принципов упорядоченности, целенаправленности при возможной неупорядоченности отдельных подсистем [13].

О важности для студентов технических вузов принципа интеллектуализации свидетельствуют ответы респондентов: развивает мышление (31 \%), ориентирует на инженерное творчество (28 \%), повышает мотивацию, интерес к познанию окружающей действительности $(44 \%)$.

При анализе ответов педагогов наибольшее значение имели следующие ответы: формирует и развивает интеллектуальную культуру студента (34 \%), воздействует на психику, эмоциональное состояние (35 \%). Дополнительно было отмечено, что педагоги рассматривают роль практической реализации принципа интеллектуализации профессиональной практики, более того, в рамках адекватного приобщения к техническому, инженерному творчеству необходимо прогнозировать этапы создания личного интеллектуального продукта. Само воздействие принципа интеллектуализации на психику студентов, педагогов воспринимают в тесной связи с психолого-педагогическими основами организации профессиональной подготовки. В рамках этой позиции требуется и важна для педагога особая развивающая среда, которая обращает студента к процессам рационализации умственных процессов, развитию интеллекта как внутреннего мира будущего бакалавра [14]. Практика реализации системы развития интеллектуальной культуры, включающей целевой, содержательный, деятельностный, критериальный компоненты (умственный кругозор, активность, интеллектуальные умения) бакалавров, строилась с учетом исследовательской, проектной деятельности [15]. 
Егорова Г. И., Семухин С. П., Чабарова Б. М. Профессиональная подготовка бакалавров...

Для определения уровня развития интеллектуальной культуры были выделены основные виды деятельности в учебной, научно-исследовательской работе по следующим показателям:

- деятельность на учебном занятии (интеллектуальная активность, решение заданий повышенной сложности, подготовка мини-проектов, выполнение исследовательского практикума);

- научно-исследовательская деятельность (участие в конкурсах, выставках, научные публикации, доклады, исследовательские задачи, проекты);

- культура умственного труда (рациональность использования времени, ответственность, планирование, целеполагание, когнитивные техники, приемы по развитию памяти, внимания, мышления);

- рефлексивная деятельность (анализ, моделирование деятельности; самоорганизация, предвидение препятствий);

- опыт коммуникативного взаимодействия (конструктивное поведение в профессиональных ситуациях, способность к сотрудничеству, проявление коммуникации, элементов общей культуры).

Показатели развития интеллектуальной культуры анализировались и учитывались на каждом курсе (с первого по четвертый) для бакалавриата высшей школы. Интерпретация контрольных срезов позволяет проследить положительную динамику развития интеллектуальной культуры. Отметим, что основные компоненты системы развития интеллектуальной культуры были внедрены в экспериментальной группе. В контрольной группе обучение строилось традиционно, согласно рабочим программам. Анализ полученных результатов показывает, что в экспериментальных группах (ЭГ) величина прироста показателей развития интеллектуальной культуры значительно выше, чем в контрольной, что доказывает решение поставленных задач и достижение цели проведенного исследования. Контрольная группа составила 128 человек, экспериментальная - 126 человек (таблица).

Результативность диагностики развития интеллектуальной культурь

\begin{tabular}{|c|c|c|c|c|c|c|c|}
\hline \multirow{3}{*}{ Группа } & \multirow{3}{*}{ Количество } & \multicolumn{6}{|c|}{ Уровень } \\
\hline & & \multicolumn{2}{|c|}{ Низкий } & \multicolumn{2}{|c|}{ Средний } & \multicolumn{2}{|c|}{ Высокий } \\
\hline & & Абс. & $\%$ & Абс. & $\%$ & Абс. & $\%$ \\
\hline \multicolumn{8}{|c|}{ Умственныий кругозор } \\
\hline Контрольная & 128 & 52 & 41,0 & 58 & 47,0 & 10 & 13,0 \\
\hline Экспериментальная & 126 & 8 & 6,0 & 62 & 48,0 & 66 & 47,0 \\
\hline \multicolumn{8}{|c|}{ Интеллектуальные умения } \\
\hline Контрольная & 128 & 80 & 63,0 & 36 & 28,0 & 12 & 9,0 \\
\hline Экспериментальная & 126 & 8 & 6,0 & 80 & 59,0 & 48 & 35,0 \\
\hline \multicolumn{8}{|c|}{ Интеллектуальная активность } \\
\hline Контрольная & 128 & 56 & 43,7 & 44 & 34,4 & 28 & 21,9 \\
\hline Экспериментальная & 126 & 12 & 9,1 & 64 & 46,9 & 60 & 44,0 \\
\hline \multicolumn{8}{|c|}{ Средние значения выраженности интеллектуальной культуры } \\
\hline Контрольная & 128 & 36 & 56,1 & 22,2 & 34,4 & 6 & 9,4 \\
\hline Экспериментальная & 126 & 4 & 5,9 & 36 & 52,9 & 28 & 41,2 \\
\hline
\end{tabular}

Таким образом, следует отметить, что в ходе работы выявили педагогическую значимость реализации принципа интеллектуализации в организации учебной, научно-исследовательской деятельности бакалавров.

Из каждого показателя развития интеллектуальной культуры было отобрано по одному индикатору (интеллектуальные умения, умственный кругозор, система знаний), которые были заложены в основу уровня развития интеллектуальной культуры. 
Результаты экспериментальной группы свидетельствуют о том, что 8 \% бакалавров первого курса и 57 \% обучающихся пятого курса вышли на творческий уровень развития интеллектуальной культуры. Как показывают наблюдения за дальнейшей деятельностью выпускников с высоким уровнем развития интеллектуальной культуры, они востребованы в научной, производственной, общественной деятельности.

Таким образом, реализация в высшей школе принципа интеллектуализации обеспечивает высокий уровень развития интеллектуальной культуры и предполагает активную включенность бакалавров в научно-практическую деятельность, ориентирующую на получение конкретного результата, что обеспечивает в будущем профессиональный успех бакалавров различных направлений.

\section{Список литературы}

1. Национальная доктрина образования Российской Федерации до 2025 года. URL: http://rg.ru/2000/10/11/doktrina-dok. $\mathrm{html}$ (дата обращения: 15.11.2019).

2. Стратегия развития воспитания в Российской Федерации на период до 2025 года. URL: http://rg.ru/2015/06/08/ vospitaniedok.html (дата обращения: 15.11.2019).

3. Пидкасистый П. И., Фридман Л. М. Психолого-дидактический справочник преподавателя высшей школы. М.: Педагогическое общество России, 1999. С. 23.

4. Ладенко И. С. Интеллектуальная культура специалиста и модели мышления // Философские науки. 1981. № 3. С. 43.

5. Ладенко И. С. Проблемы интеллектуального развития общества в условиях научно-технического прогресса // Концепция комплексных программ научных исследований. Новосибирск: Препринт, 1990. С. 67.

6. Митина Л. М., Ефимова Н. С. Интеллектуальная гибкость учителя: психологическое содержание, диагностика, коррекция: учеб. пособие. М.: Московский психолого-социальный институт, 2003. С. 12.

7. Финн В. К. Интеллектуальные системы и общество. М.: Российский государственный гуманитарный университет, 2000. C. 89.

8. Фокин Ю. Г. Преподавание и воспитание в высшей школе: методология, цели, содержание, творчество: учеб. пособие для студ. высш. учеб. заведений. М.: Академия, 2002. С. 45.

9. Х Холодная М. А. Психология интеллекта. Парадоксы исследования. Томск; М.: Барс, 1997. С. 28.

10. Егорова Г. И. Миссия образования в развитии интеллектосфреры и ноосферы глобализирующегося мира. Развитие ноосферных идей в педагогической науке и образовательной практике. СПб.: РГПУ им. А. И. Герцена; Тюмень: ТОГИРРО, 2018. $80 \mathrm{c}$.

11. Егорова Г. И. Технологии развития интеллектуальной культуры будущего специалиста: учеб. пособие для студентов, преподавателей высшей школы. Тюмень: ТюмГНГУ, 2016. 188 с.

12. Егорова Г. И., Суртаева Н. Н. Интеллектуальная компетентность при подготовке специалиста в вузе: учеб. пособие. СПб.: ИОВ РАО, 2003. С. 61.

13. Егорова Г. И. Проектирование процесса интеллектуального развития бакалавров в условиях технического вуза: материалы 17-й Междунар. науч.-практ. конф. СПб.: Экспресс, 2016. С. 358.

14. Егорова Г. И. Интеллектуальные основы социальной жизни современного человека. Методологический аспект // Вестн. Ленинградского гос. ун-та им. А. С. Пушкина. 2014. Т. 3, № 2. С. 33-42.

15. Егорова Г. И. Сущностные основы полиэтнической культуры современной образовательной системы // Известия высших учебных заведений. Социология. Экономика. Политика. 2013. № 2. С. 92-94.

Егорова Галина Ивановна, доктор педагогических наук, профессор, Тюменский индустриальный университет (ул. Володарского, 38, Тюмень, Россия, 625100). E-mail: egorovagi@list.ru

Семухин Сергей Петрович, кандидат педагогических наук, доцент, Тюменский индустриальный университет (ул. Володарского, 38, Тюмень, Россия, 625100). E-mail: semuhin.sereja@ yandex.ru

Чабарова Бибинур Мутовна, кандидат педагогических наук, доцент, Тюменский государственный университет (ул. Семакова, 10, Тюмень, Россия, 625100). E-mail: bchabarova@mail.ru

Материал поступил в редакциию 20.11.2019. 


\title{
PROFESSIONAL TRAINING OF BACHELORS IN INTELLECTUALIZATION PARAMETERS AS A LEADING GUIDANCE FOR HIGHER SCHOOL
}

\author{
G. I. Egorova ${ }^{1}$, S. P. Semukhin ${ }^{1}$, B. M. Chabarova ${ }^{2}$ \\ ${ }^{1}$ Tyumen Industrial University, Tyumen, Russian Federation \\ ${ }^{2}$ Tyumen State University, Tyumen, Russian Federation
}

The article shows a new sociocultural vision of the principle of intellectualization, focused on the development of the intellectual culture of bachelors from various perspectives. The material for the study was the development system of the intellectual culture of bachelors of higher education, where the principle of intellectualization was the backbone principle. A theoretical and methodological analysis of the leading concepts on the topic under study, a content analysis, comparative analysis. In the study of pedagogical experience, the method of classification and analogies was used. Empirical methods included questioning, conversation, comparative analysis. Statistical methods were based on mathematical analysis methods. The leading methodological approaches, the functional significance of the principle of intellectualization as a special reference point, necessary for the implementation of the new generation of FSES in higher education are shown. The psychological and pedagogical significance is disclosed, the trend of intellectualization as a leading direction and the social need for the development of Russian education in the future, forward taking into account international challenges: innovation, information, development of nano, bio, cognito, information technology, integration processes, employer requirements, is substantiated. The pedagogical view reveals the principle of intellectualization in improving the quality of bachelor's training at a university. The sociocultural aspect of the implementation of the principle of intellectualization provides professional growth, a career for bachelors in the near and long term. Particular attention is focused on the possibilities of manifesting the principle of intellectualization through the parameters of activity, content structure, level indicators of the development of intellectual culture of bachelors. The effectiveness of the implementation of the development system of the intellectual culture of bachelors is proved, where the principle of intellectualization has become the system-forming element of the system. The levels of development of intellectual culture, the main types of activity in educational, research work are determined by the following indicators: activity in the training session; research activities; Bachelor's mental work culture; reflective activity; experience of communicative interaction. Indicators of the development of intellectual culture were analyzed and taken into account at each course (from 1 to 4 courses) for undergraduate in technical and pedagogical areas. It is proved that the principle of intellectualization is a key strategy, a guideline that provides a high level of development of the intellectual culture of the future bachelor of various directions. The implementation of the principle of intellectualization is embedded in the content and activity components of education and involves the active involvement of future bachelors in scientific and practical activities, focusing on obtaining a specific result, which ensures the future professional success of bachelors.

Keywords: intellectualization, principle of intellectualization, professional training, intellectual culture, quality of training.

\section{References}

1. Natsional'naya doktrina obrazovaniya Rossiyskoy Federatii do 2025 goda [The national doctrine of the formation of the Russian Federation until 2025] (in Russian). URL: http://rg.ru/2000/10/11/doktrina-dok.html (accessed 15 November 2019). 
2. Strategiya razvitiya vospitaniya $v$ Rossiyskoy Federatsii na period do 2025 goda [The development strategy of education in the Russian Federation for the period until 2025] (in Russian). URL: http://rg.ru/2015/06/08/vospitaniedok.html (accessed 15 November 2019).

3. Pidkasistyy P. I., Fridman L. M. Psikhologo-didakticheskiy spravochnik prepodavatelya vysshey shkoly [Psychological-didactic reference book for a teacher of a higher school]. Moscow, Pedagogical Society of Russia Publ., 1999. P. 23 (in Russian).

4. Ladenko I. S. Intellektual'naya kul'tura spetsialista i modeli myshleniya [The intellectual culture of a specialist and models of thinking]. Filosofskiye nauki - Philosophical Sciences, 1981, no. 3, p. 43 (in Russian).

5. Ladenko I. S. Problemy intellektual'nogo razvitiya obshchestva v usloviyakh nauchno-tekhnicheskogo progressa [Problems of the intellectual development of society in the conditions of scientific and technological progress]. Novosibirsk, Preprint Publ., 1990. P. 67 (in Russian).

6. Mitina L. M. Intellektual'naya gibkost' uchitelya: psikhologicheskoye soderzhaniye, diagnostika, korrektsiya: uchebnoye posobiye [Intellectual flexibility of a teacher: psychological content, diagnostics, correction: textbook]. Moscow, Psychological and Social Institute Publ., 2003. P. 12 (in Russian).

7. Finn V. K. Intellektual'nyye sistemy i obshchestvo [Intelligent systems and society]. Moscow, Russian State University for the Humanities Publ., 2000. P. 89 (in Russian).

8. Fokin Yu. G. Prepodavaniye i vospitaniye $v$ vysshey shkole: metodologiya, tseli, soderzhaniye, tvorchestvo: ucheb. posobiye dlya stud. vyssh. ucheb. zavedeniy [Teaching and upbringing in higher education: methodology, goals, content, creativity: textbook for students higher institutions]. Moscow, Akademiya Publ., 2002. P. 45 (in Russian).

9. Kholodnaya M. A. Psikhologiya intellekta. Paradoksy issledovaniya [Psychology of intelligence. The paradoxes of research]. Tomsk, Moscow, Bars Publ., 1997. P. 28 (in Russian).

10. Egorova G. I. Missiya obrazovaniya v razvitii intellektosfery i noosfery globaliziruyushchegosya mira [The mission of education in the development of the intellectosphere and noosphere of a globalizing world]. Saint Petersburg, RSPU them. A. I. Herzen Publ., Tyumen, TOGIRRO Publ., 2018. 80 p. (in Russian).

11. Egorova G. I. Tekhnologii razvitiya intellektual'noy kul'tury budushchego spetsialista: uchebnoye posobiye dlya studentov, prepodavateley vysshey shkoly [Technologies for the development of intellectual culture of a future specialist: a textbook for students, teachers of higher education]. Tyumen, TSOGU Publ., 2016. 188 p. (in Russian).

12. Egorova G. I., Surtayeva N.N. Intellektual'naya kompetentnost'pri podgotovke spetsialista v vuze: uchebnoye posobiye [Intellectual competence in the preparation of a specialist at a university: textbook]. Saint Petersburg, IOV RAO Publ., 2003. P. 61 (in Russian).

13. Egorova G. I. Proyektirovaniye protsessa intellektual'nogo razvitiya bakalavrov v usloviyakh tekhnicheskogo vuza [Designing the process of intellectual development of bachelors in a technical university]. Materialy 17-y Mezhdunar. nauch.-prakt. konferentsii [Proceedings of the 17th International Scientific and Practical Conference]. Saint Petersburg, Ekspress Publ., 2016. P. 358 (in Russian).

14. Egorova G. I. Intellektual'nyye osnovy sotsial'noy zhizni sovremennogo cheloveka. Metodologicheskiy aspect [The intellectual foundations of the social life of modern man. Methodological aspect]. Vestnik Leningradskogo gosudarstvennogo universiteta im. A. S. Pushkina - Vestnik of Pushkin Leningrad State University, 2014, vol. 3, no. 2, pp. 33-42 (in Russian).

15. Egorova G. I. Sushchnostnyye osnovy polietnicheskoy kul'tury sovremennoy obrazovatel'noy sistemy [The essential foundations of the multi-ethnic culture of the modern educational system]. Izvestiya vysshikh uchebnykh zavedeniy. Sotsiologiya. Ekonomika. Politika - Proceedings of Higher Educational Institutions. Sociology. Economics. Politics, 2013, no. 2, pp. 92-94 (in Russian).

Egorova G. I., Tyumen Industrial University (ul. Volodarskogo, 38, Tyumen, Russian Federation, 625100). E-mail: egorovagi@list.ru

Semukhin S. P., Tyumen Industrial University (ul. Volodarskogo, 38, Tyumen, Russian Federation, 625100).E-mail: semuhin.sereja@yandex.ru

Chabarova B. M., Tyumen State University (ul. Semakova, 10, Tyumen, Russian Federation, 625100). E-mail: bchabarova@mail.ru 